sions on transformations. The speed of testing is, from these papers, a very pertinent variable.

Two review papers on the use of plutonium in fast fission reactors present the nuclear power facet behind the large experimental and theoretical effort covered in the Conference. Some idea of the tremendous cost involved can be inferred from the statement by one author, discussing fuel element development for one power reactor alone, that 5 million dollars will be necessary. If one multiplies this figure by the number of countries pursuing the same problem, and makes an allowance for variations in method and approach, then roughly 5 million pounds sterling may be a reasonable estimate for the whole world. This should emphasize the importance which the four countries producing significant quantities of plutonium attach to its future use as a nuclear fuel. The present stage of knowledge was very concisely summarized at the Conference, and a measure of the considerable ignorance in which nuclear scientists and engineers are still working. As a direet consequence, the book scarcely requires the recommendation which it deserves.

C. R. TottLe

\section{REACTIONS IN ORGANIC CHEMISTRY}

Name Index of Organic Reactions

By Dr. J. E. Gowan and T. S. Wheeler. Second Edition. Pp. v+293. (London: Longmans, Green and Co., Ltd., 1960.) 50s. net.

$\mathrm{O}$ RGANIC chemical processes are often named after their discoverer and this book lists alphabetically no fewer than 739 of such named reactions. A short description of each is given, usually with formulæ, and original papers or reviews are cited from which further information can be gained. There are plenty of cross-references, for example, to related processes, and, where more than one name is associated with a reaction, an entry is found under each. There are a general index based on compounds and also one based on types of reaction. The book undoubtedly satisfies a real demand, in that it provides a guide to the multitude of randomly named reactions that the organic chemist is for ever encountering and enables him to classify them chemically. It is an expanded, and much-improved, version of the author's earlier edition, which had the same title.

Though this book is most necessary, one can only yet again deplore that the need for it has arisen. Though few claim to be in favour of the practice of giving a reaction the originator's name in general chemical usage, very many of us perpetuate it in our writings and, worse, in lectures. The faults of the practice such as obscurity, lack of uniformity in naming, etc., are so well known that detailing here is unnecessary. In this book the name of Claisen is attached by itself to five different processes and, with another name, to seven others, whilo the name of Breyer by itself is given to three reactions and, in association, to six others. No fewer than twenty reactions are linked with the name Fischer. With no disrespect to the names involved or to their work, do we really need the following terms in general usage: von Braun-Rudolph modification of the Sonn-Müller reaction, Gryskiewicz-TrochimowskiMcCombie-Saunders preparation, Makarov-Zemylanski1-Prokin preparation, Padbury-Lindwall modi- fication of the Grosheintz-Fischer-Reissert reaction ? Reaction No. 630 (the Stacey esterification) was not so called by any wish of its originators, and has never been thus named at Birmingham.

Is it too late to ask that organic chemists describe reactions in chemical terms and give credit to the the discoverers by citing their references? More realistically, cannot editors of journals refuse to accopt named reactions in their publications? If a few very important processes are linked indissolubly with one name (for example, Grignard roagents), could there not be agreement on a list, as with nomenclature. In fairness to the authors of this book, it is clear from their prefaces that they do not like the practice of giving originator's names to reactions. They are dealing with the situation that already exists, and, as they say themselves, trying to combat the obscurity caused by this undesirable custom.

J. C. TATLOW

\section{SUBSONIC PLANE FLOW}

\section{The Theory of Subsonic Plane Flow}

By Dr. L. C. Woods. (Cambridge Aeronautical Series, Vol. 3.) Pp. xxii +594 . (Cambridge: At the University Press, 1961.) 120s. net.

$\mathrm{O}^{\mathrm{n}}$ all the great scientific disciplines of the twentieth century fluid dynamics takes an honourable place, and if it is not quite such a household word as radioastronomy or nuclear physics, nevertheless its contributions to our modern technological society have been no less revolutionary: the supersonic aeroplane and the guided missile are among the supreme, if misapplied, achievements of man's skill and inventiveness.

The famous physicists of the past century, however, who laid down the immense structure of classical hydrodynamics, as we now call it, made few contributions of real value to twentieth-century technology; for they were perplexed (and knew it) by the effect of the viscosity of the fluids they studied. Certainly they had their successes: as with surface waves (where viscosity is often of negligible importance) and with flow in pipes (where it is overwhelmingly important). But an acceptable theory of flight was beyond their reach and indeed awaited the scientific break-through which eventually came through the genius of Ludwig Prandt1. His conception of the action of viscosity, explained by him in both physical and theoretical terms in 1908, opened the flood-gates of modern aerodynamic research. The boundary layer had arrived !

What, therefore, are we to make of a scholarly book on fluid dynamics which virtually leaves the boundary layer unmentioned and certainly gives it no entry in 6 pages of index ? Is this volume to be regarded as a Victorian phoenix or as a startling avant-garde approach ? The former we might well dismiss at once, and with the latter we might sit happily on the fence to see what the future brings. But neither shows the right attitude, for in fact we should most heartily welcome this first exhaustive account of a certain method of solving the twodimensional Laplace equation under various types of boundary conditions.

For that is what this book is about. It is emphatically not fluid dynamics, nor is it the theory of subsonic plane flow as the title claims. There are other theories of compressible (but yet subsonic) flow, 